\title{
TÉCNICA DE FECHAMENTO PROGRESSIVO NA LAPAROSTOMIA E DESCOMPRESSÃO ABDOMINAL
}

\author{
PROGRESSIVE CLOSURE TECHNIQUE IN LAPAROSTOMY AND \\ DECOMPRESSIVE MANAGEMENT OF ABDOMEN
}

\author{
Edna Delabio Ferraz, ACBC-RJ ${ }^{1}$ \\ Orlando Marques Vieira, TCBC-R ${ }^{2}$
}

\begin{abstract}
RESUMO: É apresentada uma técnica de controle da evisceração, empregada nos casos com indicação formal de laparostomia. Através da combinação de dupla prótese temporária (tela de polipropileno e película de poliamida), realizamos o "fechamento progressivo", o qual permite a síntese primária tardia da parede abdominal, sem o risco de fístula entérica. Os resultados da primeira série de 23 pacientes (1990-1994) são comparados a outro grupo (outras técnicas de laparostomia) do mesmo hospital. A mortalidade global foi de $39,1 \%$ em nossa série, contra 55,9\% quando utilizadas outras técnicas ( $\mathrm{p}=0,003$ ), não havendo diferença entre seus índices prognósticos (Apache II). Em todos os casos em que o fechamento progressivo foi concluído (22 pacientes), a síntese primária tardia da parede abdominal foi possível, mesmo que com longos períodos de laparostomia. O emprego da técnica não aumentou o tempo de internação. A reoperação programada e o controle dos focos sépticos foram mais efetivos, com uma média de revisões de cavidade igual a 6,8 contra 1,8 no outro grupo. Nenhuma fístula e nenhuma eventração decorreram do emprego da técnica. $\mathrm{O}$ recente emprego da técnica na Síndrome Compartimental do Abdome tem demonstrado grande benefício para estes pacientes críticos. Os novos conceitos sobre a laparostomia trouxeram importantes mudanças quanto aos seus critérios de indicação e novas exigências quanto ao seu refinamento técnico.
\end{abstract}

Unitermos: Laparostomia; Peritoneostomia; Peritonite; Parede abdominal; Fechamento da parede abdominal; Fístula entérica; Hérnia; Próteses; Polipropileno; Fechamento progressivo; Síndrome compartimental do abdome.

\section{INTRODUÇÃO}

Em 1979, os franceses Hay \& Maillard, ${ }^{1}$ difundiram o conceito Ventre Laissès Ouvert" ao publicar a experiência de 64 casos de peritonite dèpassé, série iniciada em 1972 com J.P. Pujol. Este último, havia apresentado sua tese, intitulada La Non-Fermeture des Incisions Abdominales d'Urgence: Techniques e Resultats, em 1975. Desde então muito tem sido discutido sobre esta forma radical de conduzir as complicações sépticas abdominais graves.

Laparostomie, ${ }^{2}$ Evisceration Therapeutique, ${ }^{3}$ Laparostomy, ${ }^{4}$ Open Abdomen, Leave Peritoneal Cavity Open, ${ }^{5}$ e Öpen Bük, ${ }^{6}$ foram algumas das denominações sugeridas pela literatura mundial para a laparostomia (ou peritoneostomia).
Mas, a experiência de Ogilvie $(1940)^{7}$ com as feridas abdominais, na Segunda Guerra Mundial já denunciava, bem antes do advento da laparostomia, todos os aspectos da evisceração controlada e seus riscos.

A evisceração controlada, como alternativa de condução dos casos graves de peritonite associada ao fechamento tecnicamente impedido, foi a grande precursora da laparostomia. Evitar a lesão das alças expostas em condições impróprias para o fechamento da parede representa um desafio constante aos cirurgiões.

Mansberger (1973), ${ }^{8}$ empregou uma forma alternativa de "fechamento temporário" da parede, nestas condições, através da cobertura visceral com lâmina de Sylastic, a qual era mantida através de curativos à Mickulicz e sustentados por enfaixamento tipo Montgomery. Outros ${ }^{9-12}$

1. Mestre em Cirurgia Abdominal pela FM-URFJ; Cirurgiã do Hospital Universitário Clementino Fraga Filho-UFRJ; Cirurgiã do Hospital Souza Aguiar-RJ; Instrutora do ATLS/RJ pelo American College of Surgeons

2. Professor Titular do Departamento de Cirurgia da FM-UFRJ; Chefe do Serviço de Cirurgia Geral do Hospital Clementino Fraga Filho/UFRJ; Membro Titular da Academia Nacional de Medicina

Recebido em 13/12/99

Aceito para publicação em 16/5/2000

Trabalho realizado nos Serviços de Cirurgia Geral e Proctologia do Hospital Clementino Fraga Filho - Universidade Federal do Rio de Janeiro - UFRJ 
consideraram formas variadas de controle temporário da evisceração, especialmente quando ocorre deiscência de parede associada a condições sépticas do abdome.

Embora o conhecimento da fisiopatologia da peritonite tenha trazido grandes avanços no aspecto de seu tratamento cirúrgico, ${ }^{13-16}$ a introdução da laparostomia como arma terapêutica nada mais foi do que uma conseqüência da experiência clínica com a evisceração controlada.

Com a finalidade de ampliar a discussão sobre os atuais conceitos e indicação da laparostomia, apresentamos os resultados com uma primeira série de pacientes, iniciada em 1990, no HUCFF/UFRJ, nos quais nossa técnica foi empregada. Uma breve leitura sobre a evolução histórica da laparostomia é apresentada.

\section{PACIENTES E MÉTODOS}

A técnica ${ }^{17,18}$ foi empregada em 23 casos selecionados (seis mulheres e 17 homens), portadores de peritonite supurativa generalizada grave, em estudo prospectivo, e em um período de quatro anos (1990 a 1994). Foram 22 pacientes tratados no Hospital Universitário/UFRJ e um no Hospital Municipal Souza Aguiar/RJ.

Estes pacientes, tinham como denominador comum o difícil controle dos focos sépticos associado ao impedimento da síntese primária da parede abdominal. A indicação do emprego da técnica foi estabelecida tanto na primeira cirurgia, quanto na reoperação por complicações sépticas pós-operatórias, desde que fosse caracterizada a presença de um ou dos dois fatores anteriormente mencionados.

A fim de melhor delinear o perfil dos pacientes submetidos à técnica, realizamos um estudo retrospectivo, analisando outros casos de peritonite generalizada.

Numa revisão de dez anos do HU-UFRJ, coletamos 68 casos, anteriormente submetidos à laparostomia (grupo outras técnicas). Neste grupo, foram empregadas formas diversas de laparostomia (tela de polipropileno afixada à aponeurose sem recurso de proteção; pontos captonados com equipo de soro; pontos captonados com Prolene 2; poliamida fixado à pele).

Casos de peritonite generalizada tratados de forma convencional (sem laparostomia) foram utilizados como base de análise do perfil de pacientes portadores desta afecção (133 casos), no hospital principal (Tabela 1).

Foram verificados os índices Apache II, em cada um destes grupos, a fim de estabelecer o nível de gravidade entre eles.
As variáveis estudadas, sob análise estatística, foram:

- Mortalidade global

- Mortalidade na peritonite fecal/deiscência de anastomose

- Tempo de internação

- Tempo de laparostomia

- Número de revisões/reoperações

- Ocorrência de fístula

- Ocorrência de evisceração durante o tratamento

- Ocorrência de hérnia e/ou eventração

\section{A TÉCNICA}

\section{Colocação das Próteses Temporárias}

\section{Preparo da Parede, Dimensões das Próteses e Fixação}

É necessário para a fixação da tela à aponeurose, que seja realizado um descolamento prévio do tecido celular subcutâneo e plano fascial, expondo, dessa maneira, a superfície sadia do folheto anterior da bainha dos retos (considerando as incisões medianas) por cerca de $5 \mathrm{~cm}$, de forma que haja contato com a tela em extensão segura (para posterior aderência da tela à aponeurose, sem risco de desgarro). Sem isto, não é possível a tração da parede na fase de fechamento progressivo (Figura 1).

A largura da tela a ser empregada, deve ser calculada de forma a que se acomode ao diâmetro transversal da ferida abdominal, sem que cause tensão, e ocupando toda a extensão longitudinal da ferida.

A tela é fixada distante das bordas da aponeurose, através de pontos separados ou chuleio (nossa preferência), com fio de polipropileno 0 ou 2-0. Sem esta extensão de contato entre tela e aponeurose, não será possível o fechamento progressivo. Dentro de sete a dez dias, a adesão da tela à aponeurose já permite a tração sem que ocorra o descolamento da tela.

Nos portadores de estoma houve apenas necessidade de recortar a tela, de forma a adaptá-la em volta do mesmo, avançando um pouco mais na exposição da aponeurose ao seu redor para a fixação mais garantida da tela (Figura 2).

Após terminada sua fixação a cada lado, promovemos uma incisão longitudinal e mediana, a fim de que fosse aberta uma janela para a interposição da película de poliamida sobre as alças, e por sob a tela. Tendo sido inserida esta película, fechou-se a incisão mediana da tela, com chuleio de Prolene 0 ou 2-0.

Tabela 1

Peritonite Supurativa Generalizada no $\mathrm{HUCFF}^{\circ}$ - UFRJ

\begin{tabular}{l|c|c|r|r}
\hline Grupo & $N$ & Período & APACHE II & Óbitos (\%) \\
\hline Convencional (sem laparostomia) & 133 & 1984 a 1994 & 12,1 & $42(31,6)$ \\
Laparostomia (outras técnicas) & 68 & 1984 a 1994 & 13,9 & $38(55,9)$ \\
Laparostomia (polipropileno/poliamida) & 23 & 1990 a 1994 & 14,5 & $09(39,1)$ \\
\hline
\end{tabular}




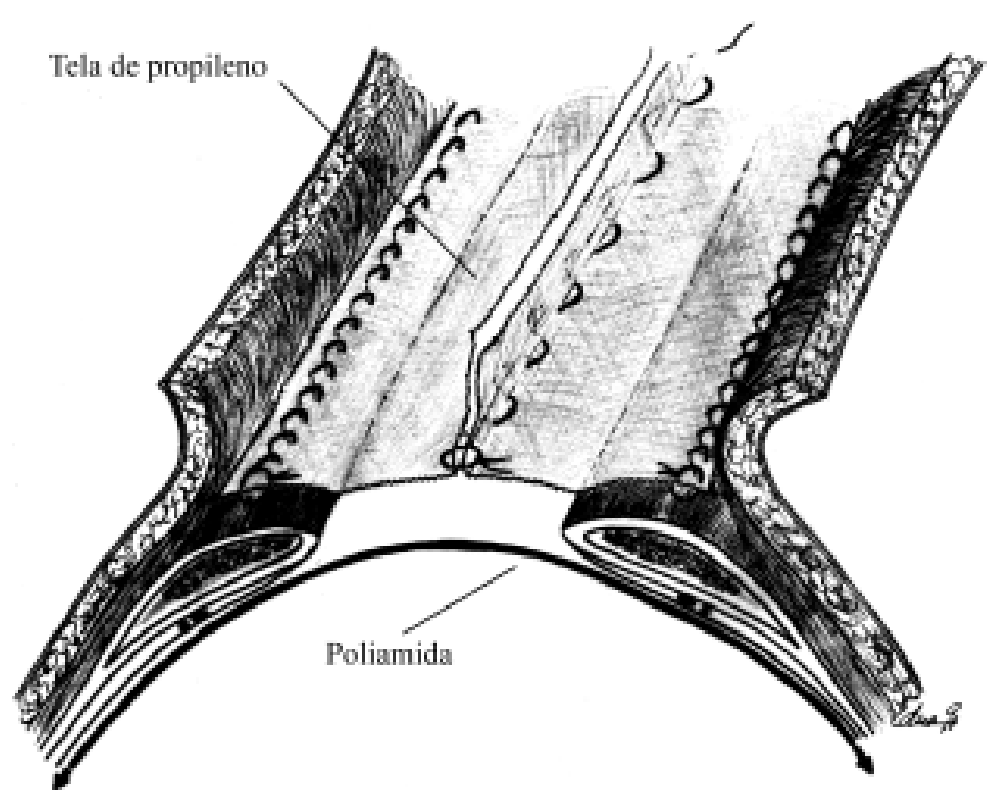

Figura 1 - Esquema de fixação da tela de Marlex e disposição da película de poliamida. Observe a extensão necessária de contato da tela sobre a aponeurose, o que exige descolamento do TCSC em cerca de $5 \mathrm{~cm}$, no mínimo. A poliamida é deixada livre sobre as vísceras, devendo alcançar as goteiras parietocólicas. Com isto, a parede abdominal fica livre e as alças protegidas.

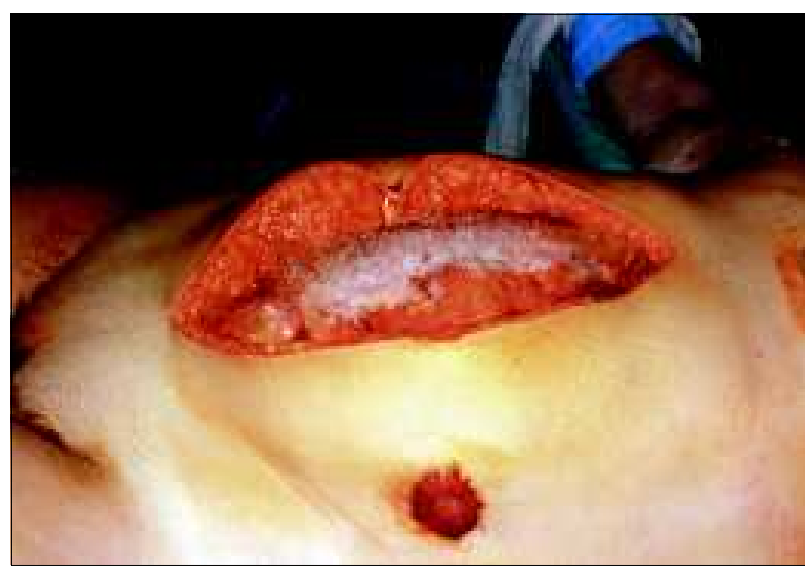

Figura 2 - Não houve impedimento para emprego da técnica nos portadores de estoma.

O tamanho da película de poliamida a ser utilizada deve ser suficiente para recobrir todas as vísceras e, se possível, alcançar as goteiras parietocólicas, devendo também ultrapassar os ângulos superior e inferior da ferida, internamente.

\section{Fechamento Progressivo}

Após estabelecida a condição de cura da peritonite, a tela receberá "chuleio-sobre-chuleio" central (diário e progressivo) a fim de que a parede abdominal seja tracionada, progressivamente, até a linha média (Figuras 3 e 4). Em nossa experiência, a tração da parede foi levada a termo em período aproximado de sete a 14 dias.

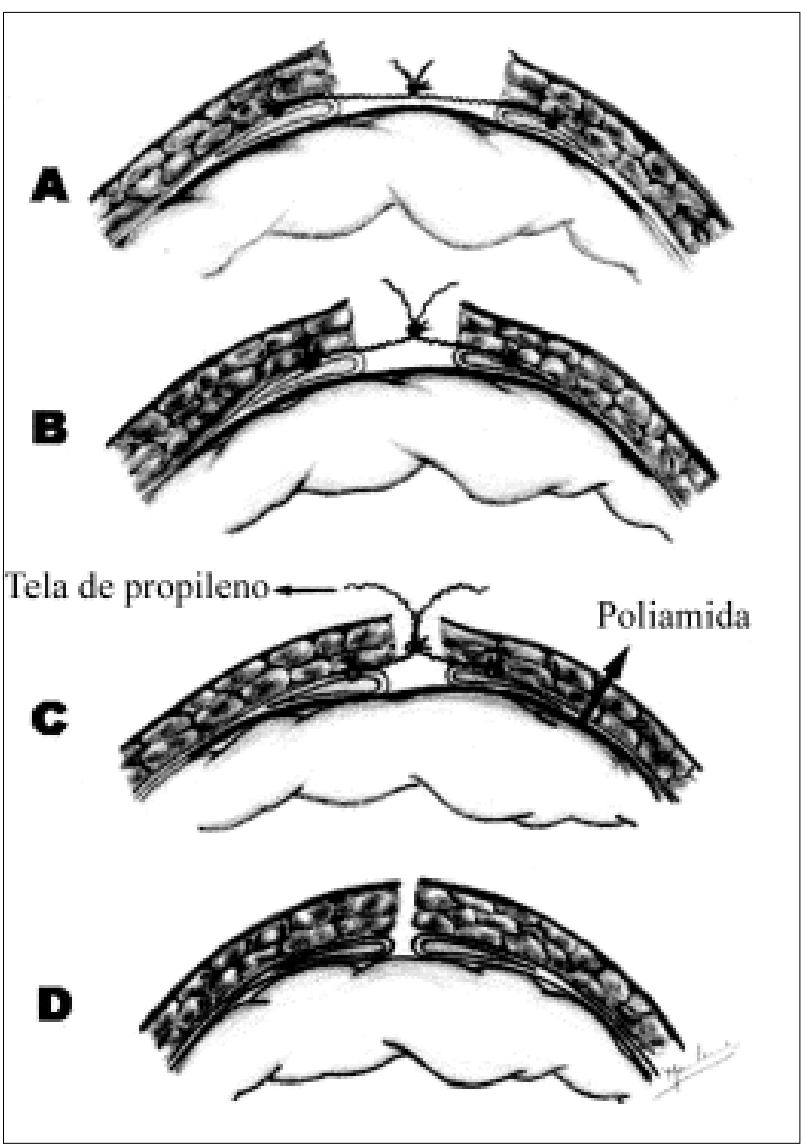

Figura 3 - Esquema do fechamento progressivo. Ao final (D), a tela de polipropileno e a poliamida são removidas e a síntese primária realizada. 


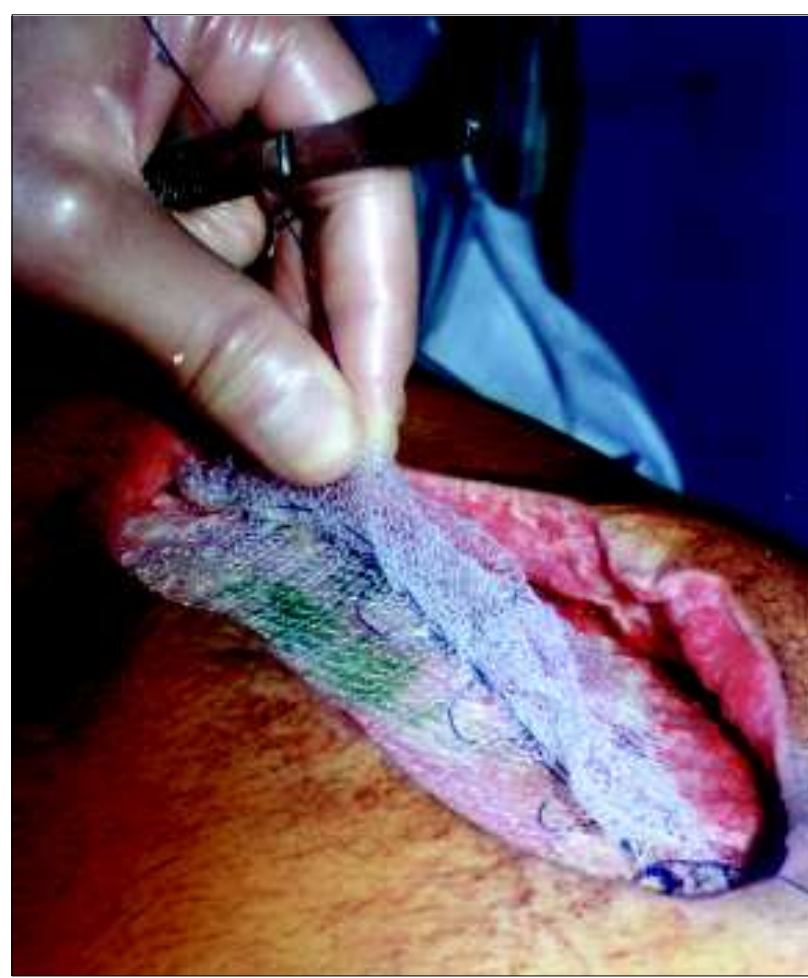

Figura 4 - Fase de aperto da tela com novo chuleio central. Observe dois planos de chuleio já realizados anteriormente. Esta fase é iniciada, em geral, após cinco-sete dias, quando a tela já se encontra aderida à aponeurose, permitindo as trações periódicas sem risco de desgarro.

Estes apertos da tela, são facilmente realizados no leito, quando o paciente já não mais necessita de reinspeção cirúrgica da cavidade. Recomendamos a utilização de diazepínico venoso a fim de relaxar a musculatura, associado a narcoanalgesia, concorrendo para minimização da dor e/ou desconforo a cada novo aperto.

Mesmo havendo necessidade de troca da película de poliamida, durante essa fase de fechamento progressivo, é possível que seja realizada no leito. $\mathrm{Na}$ fase de cura da peritonite, um tecido de granulação já recobre as terminações nervosas do peritônio parietal exposto, o que reduz sobremaneira a ocorrência de dor. É bom lembrar que esta película deve sempre ser encaixada

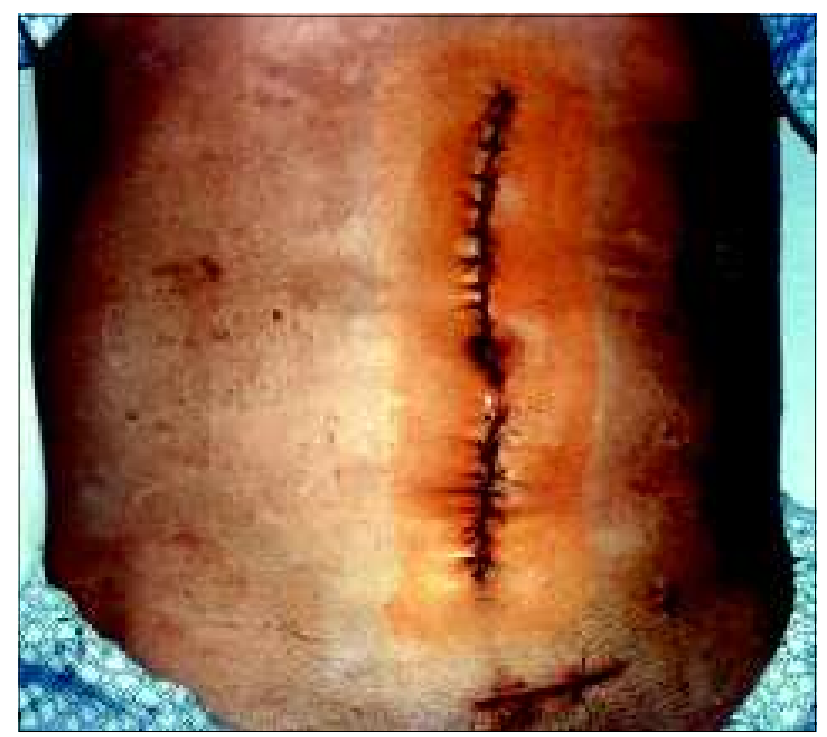

Figura 5 - Paciente submetido à um mês de laparostomia. Aspecto do abdome no $5^{\circ}$ dia de pós-operatório. Drenos a vácuo já retirados.

sob a parede, objetivando tê-la livre e reparada para o fechamento final.

\section{Síntese Primária Tardia da Parede Abdominal}

Ao final da fase de aperto da tela (fechamento progressivo), o paciente é levado à sala de operações para a síntese tardia da parede, já com as bordas devidamente aproximadas, e sem qualquer tensão.

Chamamos a atenção para a importância do emprego da película de poliamida, sem o qual não seria possível a tração progressiva da Tela de polipropileno, ou mesmo a retirada final desta, sem que houvesse qualquer tipo de dano às alças intestinais, em especial.

Desta forma, podemos fazer com que a parede alcance a posição original na linha média, acomodando-se à redução do edema visceral. Seu deslizamento sobre as vísceras é possível na presença da película de poliamida.

Sob anestesia geral, é removida toda a tela de polipropileno através de fácil descolamento. A película de poliamida é simplesmente removida, já que permanece solta

Tabela 2

Mortalidade a peritonite pós-operatória e fecal (PPO-PF)

\begin{tabular}{|c|c|c|c|c|}
\hline Grupo & $N$ & $P P O-P F$ & Óbitos & $\%$ \\
\hline Stephen \& Loewenthal (1979) & 68 & 21 & $(18 / 21)$ & 85,7 \\
\hline Convencional (sem laparostomia) & 133 & 24 & $(18 / 24)$ & 75,0 \\
\hline Laparostomia (outras técnicas) & 68 & 24 & $(19 / 24)$ & 79,2 \\
\hline Laparostomia (polipropileno/poliamida) & 23 & 9 & $(03 / 09)$ & 33,3 \\
\hline
\end{tabular}


Tabela 3

Tempo de internação, tempo de laparostomia e número de revisões de cavidade

\begin{tabular}{|c|c|c|c|c|}
\hline Grupo & $N$ & T. Internação & T. Laparostomia & № Revisões \\
\hline Laparostomia (outras técnicas) & 68 & 36 dias & $7,6 \mathrm{~d}$ & $1,8 \mathrm{x}$ \\
\hline \multirow[t]{2}{*}{ Laparostomia (polipropileno/poliamida) } & 23 & 33 dias & $15,4 \mathrm{~d}$ & $6,8 x$ \\
\hline & & & $p=0.0006$ & $p<0.0001$ \\
\hline
\end{tabular}

e livre na cavidade. A síntese da parede é concluída através de pontos separados tipo Smead-Jones, após lavagem das superfícies cruentas no espaço residual, e a pele aproximada com drenagem do espaço morto a vácuo (Figura 5).

\section{RESULTADOS}

Comparamos os três grupos estudados quanto ao nível de gravidade, através de seus respectivos índices Apache II. Não houve diferença estatística, quando analisadas suas médias, evidenciando índices semelhantes de gravidade, porém com diferença estatística nas taxas de óbito. $\mathrm{O}$ grupo submetido à nossa técnica obteve o menor dos índices (Tabela 1).

A ocorrência de peritonite por deiscência pós-operatória ou derrame fecal, foi analisada nos três grupos, com diferença estatística $(\mathrm{p}=0,03)$. Estes números são comparados aos resultados da série de Stephen e Loewenthal, demonstrando um menor índice no nosso grupo, quando comparado a todos os outros (Tabela 2).

O tempo médio alcançado com o abdome aberto em nosso grupo foi cerca de duas vezes maior (15,4 dias) do que o grupo controle (7,6 dias) não impedindo, mesmo assim, a síntese primária tardia da parede abdominal (Tabela 3).

Dos 23 casos estudados, em apenas um não foi alcançado o fechamento tardio. Neste, houve remoção precipitada e inadvertida da tela de Marlex, por suposta contaminação fecal (paciente com colostomia), sem tempo hábil para a sua reintrodução. Alertamos que, a presença de fibrina, secreção ou mesmo material entérico não inviabiliza a permanência da tela de polipropileno, que poderá ser lavada durante o ato operatório.

A média de revisões de cavidade realizadas pela técnica descrita foi quase quatro vezes maior do que no grupo controle (Tabela 3).

Em nosso grupo não foi observada a ocorrência de eventração, enquanto que no grupo controle cinco casos evoluíram para esta sequiela.

A extrusão da tela de polipropileno ocorreu em dois dos três casos em que a mesma foi empregada no grupo controle (outras técnicas). Na técnica apresentada, programa-se a remoção da tela ao final do tratamento, o que evita este tipo de ocorrência. Mesmo no caso em que foi deixada, este fato tem chances mínimas de ocorrer, por estar afixada no plano aponeurótico da parede abdominal.

A evisceração no transcurso da laparostomia ocorreu em sete casos do grupo controle (outras técnicas), enquanto que em nenhum dos nossos 23 casos.

\section{DISCUSSÃO}

Dos resultados obtidos com o emprego da técnica, os que mais nos chamaram a atenção foram:

1) a possibilidade de melhor controle dos focos sépticos, através de mais fácil acesso, nas reoperações programadas;

2) a possibilidade de descompressão abdominal, afastando o risco do fechamento por segunda intenção;

3) o risco mínimo de lesão entérica adicional, ao empregar a tela de polipropileno, pela proteção oferecida pela película de poliamida;

4) o aspecto funcional da parede abdominal (mínimo dano com possibilidade de síntese tardia e risco mínimo de incapacitação).

O controle ideal dos focos sépticos através de um melhor acesso, foi um dos nossos objetivos ao sugerir a técnica, fato não alcançado de forma efetiva com aquelas anteriormente empregadas.

Ao contrário da opinião dos que primeiramente a utilizaram, a experiência acumulada com a laparostomia veio demonstrar não ser efetiva ao empregá-la como meio de drenagem ampla da peritonite generalizada, consolidando o conceito, por nós defendido, de que não é possível tratar as peritonites supurativas difusas graves, como se fosse um "grande abscesso", apenas drenando-o amplamente.

Este fato, já havia sido observado e descrito há quase um século por John Yates, ${ }^{19}$ (1905), que afirmou com base experimental que "...é física e fisiologicamente impossível drenar a cavidade peritoneal como um todo...".

O conceito de reoperação programada, ${ }^{20-24}$ (ettapenlavage, scheduled reoperation), introduziu uma nova etapa na evolução da laparostomia, onde o alvo passou a ser o "controle dos focos sépticos" através das revisões freqüentes, e não mais a drenagem ampla como elemento fundamental. Entretanto, as técnicas empregadas nem sempre permitiam estas revisões de forma ideal. $\mathrm{O}$ abdome, com freqüência, terminava bloqueado (congelado) precocemente, tornando impedido o controle ótimo dos focos sépticos, e a parede abdominal resultava em algum tipo de sofrimento.

A proteção visceral e o controle da evisceração seguem desafiando os cirurgiões, sempre que são obrigados a indicar a laparostomia.

As sucessivas e acumuladas evidências sobre a elevada morbidez da laparostomia deveram-se, especialmente, 
ao risco de lesão entérica. Este fato exigiu maior rigor quanto aos seus critérios de indicação. Mas, algumas questões seguiram exigindo respostas. Quais as reais vantagens da laparostomia no paciente crítico portador de peritonite supurativa generalizada? Valem seus riscos?

Markgraf, ${ }^{25}$ em 1972, descreveu os efeitos deletérios do fechamento sob tensão, sobre a ventilação e o retorno venoso, apontando para os malefícios da hipertensão abdominal sobre as condições clínicas, indicando o uso temporário de tela de polipropileno, como recurso para o controle da evisceração na peritonite grave.

Estudos experimentais de Richards et al. ${ }^{26}$ (1983), apontaram para ocorrência de danos circulatórios, ventilatórios e renais sob regime de hipertensão abdominal aguda. Um ano mais tarde, Kron et al. ${ }^{27}$ (1984) sugeriram a identificação clínica da hipertensão abdominal, como critério de reoperação.

Mais recentemente, a descompressão abdominal ganha credibilidade na comunidade cirúrgica, como segundo fator determinante do sucesso na laparostomia. ${ }^{28}$

Surge, então, este novo critério de indicação, o qual relaciona-se com o controle da hipertensão abdominal aguda.

Passada a fase em que a laparostomia foi empregada de forma indiscriminada, durante quase duas décadas, os resultados convergiram para a determinação de novos princípios com critérios de indicação mais rígidos e lógicos.

Em 1996, Wittmann, Schein e Condon ${ }^{29}$ publicam de forma clara e objetiva os critérios para a indicação da laparostomia:

- condição clínica crítica impedindo reparo primário;

- edema peritoneal excessivo (SCA = síndrome compartimental do abdome) impedindo fechamento da parede abdominal (pressão > 15mmHg);

- dano maciço (avulsão ou necrose) da parede abdominal;

- impossibilidade de controlar ou eliminar o foco infeccioso;

- eliminação incompleta dos debris necróticos;

- viabilidade duvidosa do intestino;

- sangramento incontrolável exigindo packing (tamponamento com compressas).

Antigas formas de controle de evisceração, são novamente empregadas a partir da discussão do damage control (no trauma abdominal grave) e da necessidade de cobertura visceral temporária, no emprego da descompressão da SCA.

A bolsa de Bogotá é uma delas. Trata-se da cobertura das vísceras através de uma bolsa de PVC (cloreto de polivinila) improvisada a partir de coletores urinários, que são abertos e suturados à pele..$^{30}$

Este recurso, conhecido como silus, já havia sido experimentado em nosso hospital, na década de 1980, quando era empregada a película de poliamida, em lugar do PVC. Trata-se de um recurso aceitável, naqueles casos em que os pacientes encontram-se moribundos, ou seja, quando a condição clínica exige brevidade nos procedimentos. No entanto, acabou sendo abandonado por des- garrar, com freqüência, sua fixação à pele (resultando em evisceração e risco para as alças intestinais) e pela impossibilidade do fechamento da parede a posteriori. Esta experiência nos mostrou ser praticamente impossível a síntese posterior da parede abdominal, quando empregado este recurso por mais de 72 horas. Ao constatar a redução do edema visceral, a retração parietal é tal que não mais permite a síntese parietal. Em geral, estes casos não evoluem com redução do edema visceral antes de uma semana, o que afasta ainda mais a possibilidade do fechamento de parede.

Também acreditamos que a presença da hipertensão abdominal aguda na peritonite grave, seja um dos fatores que contribuem para o agravamento das condições clínica, e seu diagnóstico pode concorrer para a indicação da laparostomia como elemento adjuvante no seu tratamento.

Proteger as vísceras e, simultaneamente, reduzir o sofrimento da parede abdominal nestas circunstâncias, oferecendo chances de seu fechamento, foi outro de nossos objetivos.

Várias foram as tentativas empregadas para o controle da evisceração na laparostomia, como as próteses politetrafluoretileno (PTFE), o nylon, o teflon, o polipropileno (associados ou não ao velcro ou zíper). Tentativas menos convencionais foram experimentadas por muitos, através do emprego de meias de nylon, tela de filó, duramáter, pericárdio bovino, entre outros, além dos já conhecidos pontos captonados que danificavam sobremaneira a parede abdominal.

A tela de polipropileno ${ }^{31}$ foi a que mais ganhou adeptos. Esta foi empregada, experimentalmente e pela primeira vez, por Usher $(1958)^{32}$, que comprovou ser a prótese de maior força tênsil e de menor reatividade tecidual. Como peculiaridade exclusiva desta prótese, Usher descreveu a possibilidade da proliferação de fibroblastos por entre suas fibras, mesmo na presença de infecção, ao contrário de todas as outras.

Entretanto, esta última característica provocou o surgimento de novos problemas, aos que dela se utilizaram na laparostomia, tais como:

- a impossibilidade de fechar a parede abdominal, após tratada a peritonite, pela aderência por ela promovida, resultando em fechamento por segunda intenção;

- as fístulas entéricas pelo contato direto ou na tentativa de remoção da tela;

- a extrusão da tela ( nas feridas cicatrizadas por segunda intenção ou quando tentados recursos de cobertura do defeito abdominal, com enxerto parcial de pele).

Walsh $(1988)^{33}$ sugeriu o "fechamento primário tardio" através da plicatura da tela, mas não relatou ter removido a tela em todos os casos, em conseqüência da sua adesão e do risco de lesão entérica na tentativa de sua remoção.

D'Acampora, Lopes e Ludwig (1989) ${ }^{34}$ registraram não ser possível remover a tela de polipropileno sem lesão entérica, quando a mesma era mantida por mais de 10 dias em contato com as vísceras. 
A tela de polipropileno passou a ser abandonada, em função destes inconvenientes, resultando em novos problemas quanto ao controle da evisceração, fato este solucionado com a introdução da película de poliamida.

O fechamento impedido da parede abdominal, nestas circunstâncias críticas, foi contornado com a estratégia do fechamento progressivo criando condições ótimas para a síntese final e tardia da parede abdominal, através da associação de dupla prótese temporária.

Enquanto a tela de polipropileno atua como elemento de contenção, a película de poliamida protege as alças intestinais deixando a parede abdominal livre para as futuras trações no fechamento progressivo.

A partir do sucesso de um caso, em 1990, fomos estimulados a desenvolver um estudo prospectivo, a fim de demonstrar a eficácia da técnica nas reoperações programadas.

Em apenas um dos 23 casos, a tela não foi retirada integralmente. Tratava-se de uma criança de seis anos, submetida a reoperações múltiplas por apendicite complicada, deiscência de suturas entéricas e fascite necrótica. Neste caso, optamos por deixar a extensão de tela já aderida à aponeurose, utilizando-a, desta forma, como reforço para o fechamento, já que a parede ainda demonstrava friabilidade, quando decidido pela síntese final. Esta alternativa demonstrou ótimo resultado, não havendo qualquer complicação posterior.

Em todos os casos em que empregamos a técnica, também houve possibilidade do fechamento da pele. Recomendamos coleta de amostras de exsudato da parede, nos dias que antecedem ao fechamento, para identificação de possíveis germes terciários e cobertura antibioticoterápica necessária dos mesmos. Na síntese final da parede, a retirada da tela de polipropileno obriga a drenagem a vácuo do espaço supra-aponeurótico, resultante do descolamento da mesma.

Outro fato observado, foi a mobilização mais precoce do paciente no leito, minimizando, assim, o risco de fenômenos tromboembólicos.

Em nossa experiência mais recente, observamos ser viável o emprego da técnica, mais tardiamente, mesmo quando já utilizados, previamente, outros recursos de proteção da laparostomia, como a bolsa de Bogotá (técnica em silus). No entanto, alertamos que quanto mais precoce sua introdução, melhores seus resultados. Já tivemos a oportunidade de empregar a técnica em dois casos com síndrome compartimental, nos quais a mesma foi introduzida num segundo momento, quando melhores condições clínicas eram mais oportunas (três-quatro dias após).

Atualmente temos recorrido aos plásticos (polietileno) esterilizados com óxido de etileno (como os de capa para câmera de videolaparoscopia) em substituição à película de poliamida.

Destacamos que, além de ter permitido melhor controle da condição séptica abdominal, a técnica descrita pode oferecer aos sobreviventes, maiores chances de reintegração profissional e mais breve retorno ao convívio social.

Os novos conceitos, conhecimentos e a experiência clínica acumulada, apontam para soluções inovadoras quando empregado o tratamento radical da peritonite secundária generalizada grave, através da laparostomia.

Os resultados obtidos com a nossa experiência implicaram a padronização desta técnica no Serviço de Cirurgia Geral e Proctologia do HUCFF/UFRJ, no tratamento das peritonites secundárias generalizadas graves, com indicação criteriosa de laparostomia, tanto no trauma quanto no abdome séptico (primário ou pós-operatório).

\begin{abstract}
A new technique to preserve the abdominal wall in laparostomies will be presented. This technique proposes a different solution to minimize morbidity related to laparostomy using a double temporary prosthesis of polypropylene mesh and polyamide sheet. With the use of these prosthesis materials, a minimum parietal damage was shown and this technique allowed a delayed primary synthesis of the abdominal wall through progressive closure. Our results in the first 23 patient's group (1990-1994) will be show and compared to another group treated, at the same hospital by another laparostomy technique. In both groups the risk had being evaluated by Apache II score and there was no statistical difference between them, but the mortality rate was 39,1\% in the first group and 55,9\% in the second $(p=0,003)$. Even when there was a long time of "open abdomen" the delayed primary synthesis of the abdominal wall was accomplished (with the progressive closure technique). The scheduled operations to control septic focus were more easily performed. There was no fistula formation resulting from the use of the prosthesis and technique. The recent employment of this technique in patients with Compartimental Abdominal Syndrome, had shown good results. Newer understanding of laparostomy concepts had brought major alterations in its indication and technica improvement as well.
\end{abstract}

Key Words: Laparostomy; Open abdomen; Peritonitis; Abdominal wall; Abdominal wall closure; Fistulae; Hernia; Prosthesis; Polypropylene; Progressive closure; Abdominal compartimental syndrome. 


\section{REFERÊNCIAS}

1. Hay JM, Duachatelle P, Maillard JN, et al - Les Ventres Laissès Ouverts. Chirurgie 1979;105:508-510.

2. Fagniez PL, HAY JM, Regnier B, et al - La Laparostomie: Une Technique d'Exception dans le Traitment des Péritonites Dépassès. Concours Med 1979;101:4569-73.

3. Champault G, Psalmon F, Patel JC, et al - L'evisceration : Element Therapeutique des Peritonites. Nouv Press Med 1979;7:1349.

4. Mughal MM, Bancewicz J, Irving MH - "Laparostomy": a Technique for the Management of Intractable Intraabdominal Sepsis. Br J Surg 1986;73:253-259.

5. Steinberg D - On Leaving the Peritoneal Cavity Open in Acute Generalized Suppurative Peritonitis. Am J Surg 1979; 137:216-220.

6. Broomé A, Hansson L, Lundgren F, et al - Open Treatment of Abdominal Septic Catastrophies. World J Surg 1983;7:792-796.

7. Ogilvie WH - The Late Complications of Abdominal War Wounds. The Lancet 1940;31:253-258.

8. Mansberger AR, Kang JS, Beebe HG, et al - Repair of Massive Acute Abdominal Wall Defects. J Trauma 1973;13:766-774.

9. Araújo GF, Costa DS, Guarino JL, et al - Tratamento das Peritonites Difusas Graves com Abdome Aberto Protegido com Tela de Filó Associado a Reoperações Planejadas. Rev Bras Cir 1991;81:163-167.

10. Boyd WC - Use of Marlex Mesh in Acute Loss of the Abdominal Wall due to Infection. Surg Gynecol Obst 1977; 144:251-252.

11. Fagniez PL - La Prevention des Lesions Intestinales lors des Eviscerations. Nouv Press Med 1978;7:1117.

12. Makhocha NS - "Open Method for Treatment of Diffuse Purulent Peritonitis". Khirurgia (Mosk) 1984;8:124127.

13. Maddaus MA, Ahrenholz D, Simmons RL - The Biology of Peritonitis and Implications for Treatment. Surg Clin Nort Am 1988;68:431-443.

14. Rotsteins OD, Meakins JL, et al.: Diagnostic and Therapeutic Challenges of Intra-abdominal Infections. World J Surg 1990;14:159-166.

15. Sawyer RG, Rosenlof, LK, Adams RB et al - Peritonitis Into the 1990's: Changing Pathogens and Changing Strategies in the Critically Ill. Am Surg 1992;58:8287.

16. Stephen M, Loewenthal J - Continuing Peritoneal Lavage in High Risc Peritonitis. Surgery 1979;85:603-606.

17. Ferraz ED, Vieira OM - Laparostomia: Técnica Alternativa para Fechamento Progressivo - Combinação de Tela de Marlex e Sterylpack - Comunicação Preliminar. Rev Col Bras Cir 1992;19:272-273.

18. Ferraz, ED - Peritoneostomia: Proposta de Técnica SemiAberta com Emprego de Tela de Propileno e Filme de Poliamida - Estudo Comparativo com as Técnicas Usuais. Dissertação de Tese de Mestrado, Curso de Pós Graduação em Cirurgia Abdominal, Rio de Janeiro, UFRJ, Faculdade de Medicina, 1995, 121 f., ilustr.

19. Yates JL - An Experimental Study of the Local Effects of Peritoneal Drainage. Surg Gynecol Obst 1905;1:473492.

20. Rasslan S, Silva RA, Prado PA, et al - Reoperações Programadas no Tratamento das Infecções Peritoniais Graves. Rev Paul Med 1998;106:81-84.
21. Teichmann W, Wittmann DH, Andreone PA - Scheduled Reoperations (Ettappenlavage) for Diffuse Peritonitis. Arch Surg 1986;121:147-152.

22. Hedderich GS, Wexler MJ, Mclean APH, et al - The Septic Abdomen: Open Management With Marlex Mesh With a Zipper. Surgery 1986;99:399-408.

23. Birolini D - "Princípios Básicos do Tratamento da Peritonite Aguda Secundária". In: Frederico Filgueiras POHL(ed) - Manual do Abdome Agudo Infeccioso CBC, 1990, pp 163-190.

24. Schein M, Saadia R, Freinkel Z, et al - Agressive Treatment of Severe Diffuse Peritonitis: a Prospective Study. Br J Surg 1998;75:173-176.

25. Markgraf WH - Abdominal Wound Dehiscence: A Technique for Repair with Marlex Mesh. Arch Surg 1972;105:728-732.

26. Richards WO, Scovill W, Shin B, et al - Acute Renal Failure Associated with Increased Intra-abdominal Pressure. Ann Surg 1983;197:183-187.

27. Kron IL, Harman PK, Nolan SP - The Measurement of Intra-abdominal Pressure as a Criterion for Abdominal Re-exploration. Ann Surg 1984;199;28-30.

28. Eddy VA, Nunn C, Morris JAJr - Abdominal Compartment Syndrome: The Nashville Experience. Surg Clin North Am 1997;77:801-812.

29. Wittmann D, Schein M, Condon RE - Management of Secondary Peritonitis. Ann Surg 1996;224:10-18.

30. Anunciação J, Hoppen R, Borghetti V - Bolsa de Bogotá. Rev Med HSVP 1998;10:58-60.

31. Jones RV - Physical Properties of Marlex Mesh 50 Ethylene Polymer. Indust \& Engeneer Chem 1956;48:1153.

32. Usher FC, Wallace AS - Tissue reaction to Plastics : A Comparison of Nylon, Orlon, Dacron, Teflon and Marlex. Arch Surg 1958;76:997-999.

33. Walsh GL, Chiasson P, Hedderich G, et al - The Open Abdomen - The Marlex Mesh and Zipper Technique: A Method of Managing Intraperitonial Infection. Surg Clin North Am 1988;68:25-40.

34. D'Acampora AJ, Lopes A, Ludwig FC - Peritoneostomia no Tratamento da Peritonite Difusa: Análise de Onze Casos. Arq Cat Med 1989;18:15-19.

\section{ENDEREÇO PARA CORRESPONDÊNCIA}

Dra. Edna Delabio Ferraz

Rua Vaz de Toledo, 204/502

20780-150 - Rio de Janeiro - RJ

E-mail: ednaferraz@imagelink.com.br 